\title{
Las negligencias más comunes en la práctica odontológica.
}

\author{
The most common negligence in dental practice.
}

\author{
Agustín Tiol-Carrillo*
}

\section{RESUMEN}

Para el adecuado ejercicio de la odontología, los procedimientos realizados deben ejecutarse apegándose en todo momento a las normas y principios éticos propios de la profesión. Cuando un odontólogo decide, por voluntad propia, ejercer la profesión sin apegarse a dichos principios, se considera que actúa con negligencia. La negligencia se caracteriza por ser un acto indebido, en el cual el profesional ejecuta por voluntad propia acciones injustificables capaces de producir daños en la salud de los pacientes o en el pronóstico de un tratamiento. Los actos negligentes, además de atentar contra la integridad del paciente, ponen en riesgo a los profesionales de la salud que los cometen de sufrir consecuencias legales derivadas de dichos actos. El objetivo del presente artículo consiste en definir el concepto de negligencia, describir las formas más comunes en las que ésta se comete durante la consulta odontológica así como sus posibles consecuencias legales, ilustrándolas a su vez con la breve presentación de algunos casos.

Palabras clave: Odontología legal, mala praxis, negligencia, responsabilidad profesional.

\section{ABSTRACT}

For the proper practice of dentistry, the procedures performed must be carried out adhering at all times to the standards and ethical principles of the profession. When a dentist voluntarily decides to practice the profession without adhering to these principles, he is considered to be acting negligently. Negligence is characterized as an improper act, in which the professional voluntarily executes unjustifiable actions capable of causing damage to the health of patients or the prognosis of a treatment. Negligent acts, in addition to threatening the integrity of the patient, put health professionals at risk who commit legal consequences derived from these acts. The aim of this article is to define the concept of negligence, to describe the most common ways in which it is committed during the dental practice as well as its legal consequences, illustrating them in turn with a brief presentation of some cases.

Keywords: Legal odontology, malpractice, negligence, professional responsibility.

\section{INTRODUCCIÓN}

$\mathrm{L}$ a odontología, así como cualquier otra rama de la salud, cuenta con parámetros que permiten asegurar la calidad en los servicios prestados, dichos parámetros son inculcados y exigidos a los alumnos que cursan la licenciatura en odontología, ya sea en universidades públicas o privadas. Entre ellos, se incluyen un conveniente diagnóstico a través de una exhaustiva elaboración del expediente clínico, toma de series radiográficas y la ejecución del tratamiento de la forma más higiénica posible mediante la utilización de instrumentos estériles.

Un tratamiento odontológico se considera exitoso cuando éste se ejecuta de forma conveniente y se apega a los principios elementales de la profesión. Sin embargo, es una realidad que numerosos odontólogos, una vez que egresan de la universidad, abandonan voluntariamente las buenas prácticas adquiridas durante su formación profesional, argumentando que les absorbe tiempo valioso en su práctica clínica, que su consulta es más eficaz al no realizarlas o simplemente por no considerarlas importantes.

\footnotetext{
* Especialista en Estomatología Pediátrica. Máster en Odontología Legal y Forense. Profesor en la UAM Xochimilco y Universidad Anáhuac México Campus Norte. Perito en Odontología en la Unidad de Peritos Judiciales, Poder Judicial de la Federación. México.

Recibido: 28 de octubre de 2021. Aceptado: 11 de enero de 2022.

Citar como: Tiol-Carrillo A. Las negligencias más comunes en la práctica odontológica. Rev ADM. 2022; 79 (1): 32-37. https://dx.doi.org/10.35366/103816
}

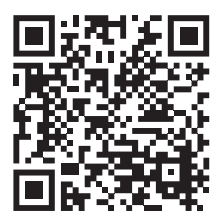


Lo anterior es en extremo delicado, ya que la omisión de determinadas acciones podría ocasionar daños a la salud de un paciente, generando como consecuencia algún tipo de responsabilidad profesional por mala práctica médica.

Se conoce como negligencia el incumplimiento de los principios elementales de una profesión, ${ }^{1,2}$ o en otras palabras, incurrir en actos indebidos y desatención omitiendo lo que se debe hacer o haciendo lo que no se debe hacer. ${ }^{3,4}$ Lo que resulta más grave del acto negligente es que quien lo ejecuta, es totalmente consciente de los errores cometidos y de sus posibles consecuencias para sí mismo y/o para sus pacientes.

El objetivo del presente artículo consiste en definir el concepto de negligencia y vincularlo con el desempeño profesional del odontólogo en la práctica odontológica diaria, así como resaltar las consecuencias legales de los actos negligentes.

\section{OMISIONES EN LA ELABORACIÓN DE UN EXPEDIENTE CLÍNICO}

Toda vez que un paciente acude a consulta dental por primera vez, es necesario que el odontólogo conozca detalladamente el estado de salud de su paciente, lo anterior puede lograrlo a través de la elaboración de un expediente clínico que permite al profesional allegarse de la información mínima necesaria para poder brindar una atención de calidad y con la menor cantidad de riesgos posibles. Además de permitir al odontólogo conocer información relevante sobre su paciente, el expediente clínico es tam- bién un registro de las actividades realizadas en la atención odontológica prestada, ${ }^{5}$ donde cita tras cita se hace constar por escrito el estado y la evolución del paciente.

La omisión de la elaboración del expediente clínico es una de las negligencias más comunes en la práctica odontológica. ${ }^{4}$ Es bastante frecuente que el odontólogo comience a atender a los pacientes sin haberlos interrogado previamente, poniendo en riesgo su salud y seguridad (tras la omisión en el interrogatorio sobre antecedentes personales patológicos, no patológicos y heredofamiliares) así como el prestigio y la seguridad del propio odontólogo tras decidir voluntariamente no elaborar la documentación médico-legal, el único elemento que puede auxiliarle en caso de quejas o inconformidades por parte de un paciente inconforme por la atención brindada.

Asimismo, si se cuenta con un expediente clínico es común encontrarlo incompleto, con desorden en su estructura, con defectos como ilegibilidad en los registros asentados, uso de abreviaturas, con omisiones importantes en la historia clínica y notas de evolución. ${ }^{6}$

\section{FALTA DE HIGIENE EN LA EJECUCIÓN DE TRATAMIENTOS ODONTOLÓGICOS}

La cavidad bucal es un sitio anatómico en extremo contaminado que se encuentra continuamente hidratado por saliva y habitado por alrededor de 6,000,000 de bacterias, ${ }^{7}$ mismas que son las principales responsables de las enfermedades más comunes que afectan a los dientes: la caries y la enfermedad periodontal.
Figura 1:

El uso de dique de hule en la realización de procedimientos de restauración y tratamientos de endodoncia es de vital importancia

por higiene, y para evitar accidentes transoperatorios como

laceración de tejidos blandos o broncoaspiración de instrumental.

El no utilizarlo puede ser categorizado como negligencia.


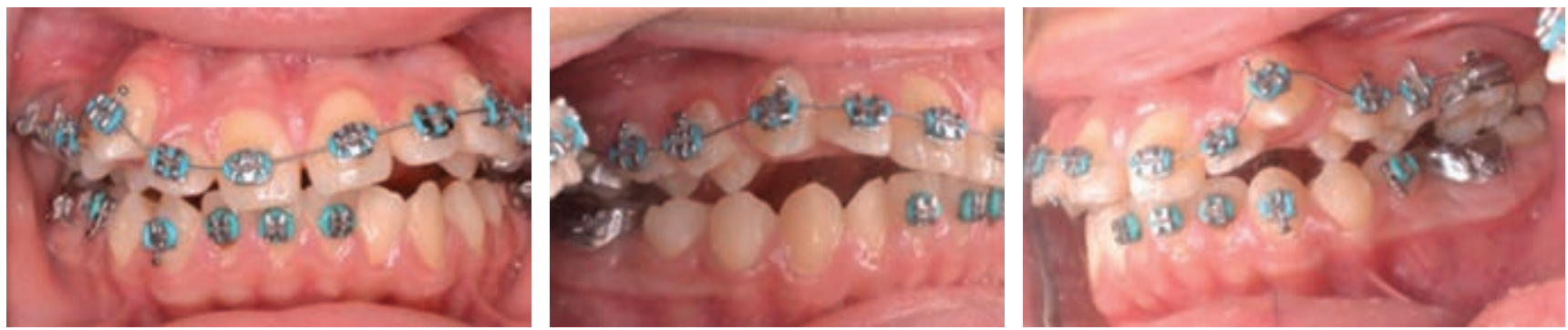

Figura 2: Consecuencias de un tratamiento ortodóncico realizado por personal imperito, quien, sin tomar en cuenta la magnitud de las fuerzas aplicadas, generó un daño importante en la dentición del paciente.
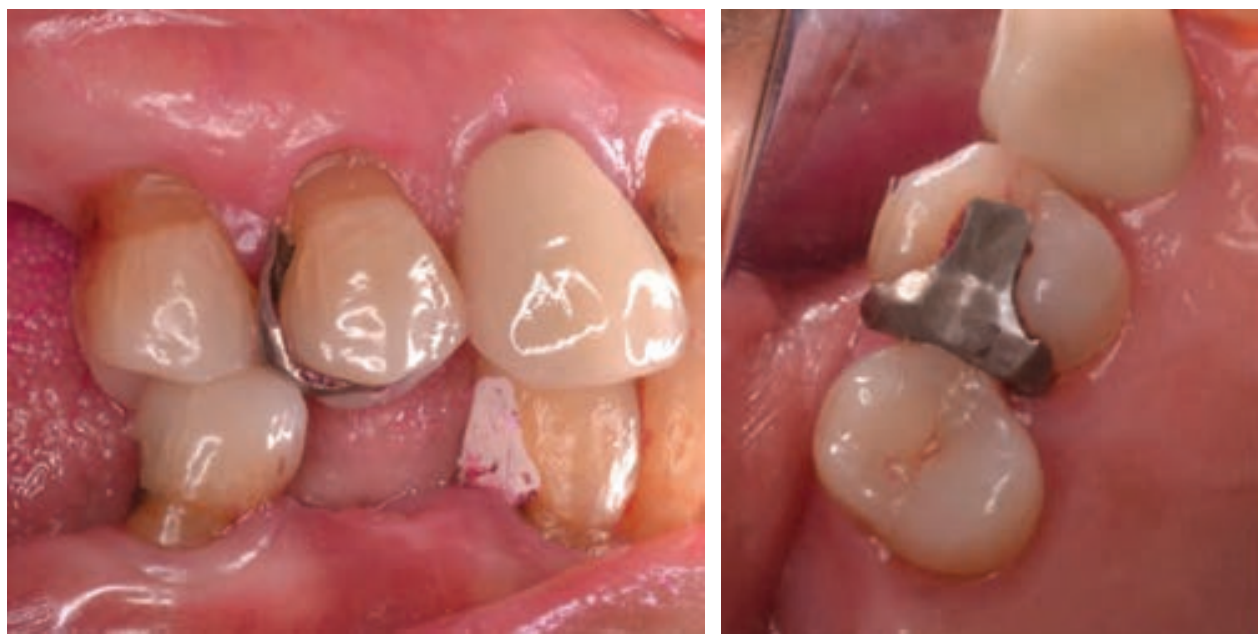

Figura 3:

En este caso se observa una restauración indirecta con importantes desajustes marginales cementada en un primer premolar superior. Cabe destacar que es obligación del odontólogo verificar un adecuado ajuste marginal de toda restauración antes de cementarla.

Cuando se realizan procedimientos de operatoria dental y tratamientos de endodoncia, la higiene y el adecuado control de fluidos son de suma importancia para un pronóstico exitoso, lo cual se logra exclusivamente mediante un adecuado aislamiento del campo operatorio con dique de hule.

El dique de hule, creado por Barnum en 1864, es considerado como un método práctico, aséptico y seguro, tanto para el paciente como para el mismo odontólogo, que permite delimitar el área de trabajo manteniéndola libre de fluidos y que mejora notablemente la visibilidad del sitio que está siendo intervenido. ${ }^{8}$

La omisión de la colocación del dique de hule en la ejecución de procedimientos operatorios es sin duda un acto negligente que afecta de manera significativa la calidad y el pronóstico del tratamiento realizado, ${ }^{9}$ ya que ejecutarlo sin un adecuado control de fluidos y contaminantes, el riesgo de fracaso del tratamiento se incrementa considerablemente.

Además, el dique de hule es una barrera física que permite trabajar con seguridad, evitando el riesgo de ingesta o aspiración de cuerpos extraños durante el tratamiento.

Resulta abrumador que, pese a sabiendas de los efectos negativos de no colocar dique de hule, numerosos odontólogos quieren y aceptan trabajar en ausencia de éste, argumentando que no es un elemento necesario para el procedimiento que se realiza o que absorbe mucho tiempo su colocación, siendo que desde el siglo XIX se evidenciaron las virtudes del dique de hule para un buen pronóstico de cualquier tratamiento odontológico, endodóncico o de rehabilitación (Figura 1).

Por otro lado, se evidencian numerosas faltas en el control de infección en la práctica dental, por ejemplo, el no utilizar barreras de protección entre cada paciente, o bien, el omitir el lavado de manos antes y después de atender a cada paciente. Existe literatura que sustenta que son los mismos profesionales de la salud quienes ocasionan numerosas infecciones asociadas a la atención médica tras omitir técnicas de asepsia y antisepsia en la práctica clínica diaria. ${ }^{10}$ 
Es bastante frecuente que se omita el lavado de manos o no se realice de manera adecuada, pensando erróneamente que los guantes serán el método físico que proteja al odontólogo del paciente y viceversa, siendo que, para un adecuado control de infección se requiere un correcto lavado de manos en combinación con el uso de guantes nuevos por cada paciente. ${ }^{11}$

En este mismo tenor, es altamente contaminante el manipular objetos del consultorio como manijas de las puertas o cajones o documentos con los guantes puestos, siendo éste un acto negligente ejecutado con gran frecuencia. ${ }^{10}$

\section{Impericia en la realización de procedimientos}

Todo cirujano dentista, tras haber concluido la licenciatura en odontología, cuenta con los conocimientos mínimos necesarios para resolver las afecciones bucodentales de la población en general; no obstante, existen casos más complejos que otros, y es también responsabilidad del odontólogo determinar si la resolución del caso está a su alcance o no, y en cuyo caso, remitir al paciente con un especialista.

A pesar de ser una realidad, es prácticamente nula la literatura que sustente la impericia en la ejecución de determinados procedimientos por parte del cirujano dentista de práctica general que ameritan conocimientos especializados, y que los lleva a cabo a pesar de carecer de dichos conocimientos y destrezas necesarias poniendo en riesgo la salud del paciente, tal es el caso de la especialidad en ortodoncia, prótesis, cirugía o implantología (Figuras 2 a 4).

El artículo 79 de la Ley General de Salud especifica que para el ejercicio de actividades profesionales en el campo de la odontología se requiere de títulos profesionales y certificados de especialización que hayan sido legalmente expedidos y registrados por las autoridades educativas competentes, ${ }^{12}$ por lo que resulta importante que todo odontólogo que no cuente con título de especialidad, y por ende, carezca de las habilidades y conocimientos para resolver la problemática de un paciente determinado, se abstenga de hacerlo y lo remita con prontitud al especialista.

Un acto negligente de mayor gravedad es quien ejerce la profesión sin contar con el título y cédula legamente expedidos por la autoridad educativa competente (Figura 5), acción que puede ser considerada como un delito y que además, contraviene numerosos artículos de la Ley Federal del Trabajo. Dentro de los más importantes

Figura 4:

Prótesis fija anterior de seis unidades mal ajustada colocada sobre dos pilares con escasa estructura dental remanente.


Figura 5:

Paciente que refiere haber acudido a un consultorio para recibir atención y a quien se le colocó una restauración en los dientes anteriores confeccionada probablemente con plastilina epóxica (Plastiloka). 
destaca el artículo 29 que especifica que serán sancionadas aquellas personas que sin tener el título profesional legalmente expedido actúen de manera habitual como profesionistas, el artículo 63 que indica que si una persona se atribuye el carácter de profesionista sin tener título o ejerza actos propios de la profesión, será castigado de conformidad con el artículo 250 del Código Penal y el artículo 68 que especifica que no podrá cobrar honorarios aquella persona que preste servicios profesionales sin contar con título profesional. ${ }^{13}$

\section{Marco jurídico encaminado a sancionar actos negligentes}

Si bien en nuestra legislación no existe el delito de negligencia médica, existen diferentes vías por las cuales dichos actos pueden ser sancionados de acuerdo con su gravedad.

En primer lugar, el artículo 228 del Código Penal Federal menciona que todo profesionista será responsable de los delitos dolosos o culposos que produzca en el ejercicio de su profesión, y que además, estará obligado a reparar el daño producido por sus actos propios y por los de sus auxiliares. Por tanto, si derivado de un acto negligente se genera una inconformidad por parte de un paciente, el odontólogo está obligado a responder ante ese acto realizado voluntariamente. ${ }^{14}$

Asimismo, el artículo 1910 del Código Civil Federal menciona que quien obrando ilícitamente o contra las buenas costumbres cause un daño a otro, está obligado a repararlo. Es muy probable que el actuar negligente de un profesional de la salud culmine en daños a la salud del paciente, ${ }^{15}$ y por consecuencia, este artículo será aplicable para todo odontólogo que sea responsable de daños a la salud de su paciente por no haber hecho lo debido o haber ejecutado lo indebido.

Cuando se desarrolla un caso jurídico por mala práctica médica, el esclarecimiento de los hechos estará a cargo de peritos, quienes basándose en su vasta experiencia, fincarán o deslindarán responsabilidades en el odontólogo acusado o el paciente inconforme. Para ejecutar lo anterior se requiere de pruebas testimoniales y documentales siendo el expediente clínico, con sus respectivos documentos que lo constituyen, un elemento sustancial en estos casos, a través del cual se podrá confirmar o refutar de la forma más objetiva posible la responsabilidad profesional del odontólogo.

Los peritos determinarán lo anterior verificando el adecuado desempeño por parte del odontólogo durante la atención de dicho paciente confirmando que el profesional que haya procedido correctamente dentro de los principios científicos y técnicos aplicables al caso y generalmente aceptados dentro de la profesión que se trate, si el odontólogo dispuso de los instrumentos, materiales y recursos que debieron emplearse atendidas las circunstancias del caso, si en el curso del trabajo se tomaron las medidas indicadas para obtener éxito, si se dedicó el tiempo necesario para desempeñar correctamente el tratamiento, y considerar cualquier otra circunstancia que en el caso especial pudiera haber influido en la deficiencia o fracaso del servicio prestado. Lo anterior está claramente descrito en el artículo 34 de la Ley Reglamentaria del Artículo $5^{\circ}$ constitucional relativo al Ejercicio de las Profesiones en la Ciudad de México. ${ }^{16}$

Como se podrá observar, todo profesional de la salud, en caso de resultar responsable, será sancionado no por la negligencia (considerada como una conducta primaria), sino por las consecuencias derivadas de la misma que fueron causantes directas de delitos o daños a un paciente.

\section{CONCLUSIÓN}

Como se habrá observado a lo largo del presente artículo, la negligencia es un acto en el que comúnmente incurren numerosos profesionales de la salud y que se caracteriza por ejecutar de manera voluntaria determinadas acciones u omisiones indebidas que produzcan daños a la salud de un paciente o al pronóstico de un tratamiento. La negligencia es además, un acto con posibles consecuencias legales para quien lo ejecuta por el riesgo inminente de daños y perjuicios a los pacientes.

La mejor recomendación que se puede ofrecer a todo odontólogo para evitar problemas legales, es ejercer la profesión apegándose en todo momento a los principios éticos y deontológicos que norman la odontología, absteniéndose en todo momento de prácticas negligentes por comodidad propia, desidia o por indiferencia ante la salud de sus pacientes.

\section{REFERENCIAS}

1. García-Solís E, Gómez-Vázquez P, Arispe-Castillo LM. Negligencia, imprudencia, impericia: análisis de casos 2010-2014 en la Comisión de Arbitraje Médico del Estado de Campeche. Rev CONAMED. 2015; 20 (3): 111-116.

2. Briseño CJM. La responsabilidad profesional en odontología. Rev ADM. 2006; 63 (3): 111-118.

3. Tamayo J. La relación médico paciente y la mala praxis médica. Revista Novedades Jurídicas. 2007; 4 (19): 12-23.

4. Astudillo M, Chinchilla D, Sarabia L. Mala praxis odontológica: Artículo de revisión. Rev Venez Invest Odont IADR. 2015; 3 (2): 146-170. 
5. Lupa NS, Yacaman HR, Martínez JE, Ruelas RV. La relevancia del expediente clínico para el quehacer médico. An Med (Mex). 2015; 60 (3): 237-240.

6. Carmona-Mejía B, Ponce-Gómez G. Evaluación del expediente clínico integrado y de calidad en pacientes de cirugía programada. Rev CONAMED. 2014; 19 (3): 117-127.

7. Cruz QSM, Díaz SP, Arias SD, Mazón BGM. Microbiota de los ecosistemas de la cavidad bucal. Rev Cubana Estomatol. 2017; 54 (1): 84-99.

8. Delgado MM. Aislamiento total con dique de hule. Requisito ineludible en procedimientos operatorios. Odontología Actual. 2016; 13 (158): 18-19.

9. Tiol-Carrillo A. El peritaje odontológico forense. Rev Odont Mex. 2016; 20 (3): 154-158.

10. Fluent MT. Hand hygiene in the dental setting: reducing the risk of infection. Compend Contin Educ Dent. 2013; 34 (8): 624-627.

11. Girou E, Chai SH, Oppein F, Legrand P, Ducellier D, Cizeau F et al. Misuse of gloves: the foundation for poor compliance with hand hygiene and potential for microbial transmission? J Hosp Infect. 2004; 57 (2): 162-169.

12. Ley General de Salud. Cámara de Diputados. 2021.

13. Ley Federal del Trabajo. Cámara de Diputados. 2021.

14. Código Penal Federal. Cámara de Diputados. 2021.

15. Código Civil Federal. Cámara de Diputados. 2021.

16. Ley Reglamentaria del Artículo $5^{\circ}$ Constitucional, Relativo al Ejercicio de las Profesiones en la Ciudad de México. Cámara de Diputados. 2021.

Conflicto de intereses: El autor declara no tener ningún conflicto de intereses.

Correspondencia:

Agustín Tiol-Carrillo

E-mail: agustintiolcarrillo@gmail.com 